\title{
Carbon nanomaterials for supercapacitors: two electrode scheme
}

\author{
Maxim V. Popov ${ }^{1,2-}$, Alexander G. Bannov ${ }^{2}$, and Stepan I. Yusin ${ }^{2}$ \\ ${ }^{1}$ N.D. Zelinsky Institute of Organic Chemistry Russian Academy of Sciences, 119991, Moscow, \\ Russia \\ ${ }^{2}$ Novosibirsk State Technical University, 630073, Novosibirsk, Russia
}

\begin{abstract}
In this paper, the electrochemical and texture characteristics of electrode materials made of a number of promising carbon materials for supercapacitors were considered. Carbon nanofibers, thermally expanded graphite, and activated carbon derived from rice hulls were used as electrodes for supercapacitors. The paper presents a technique of synthesis of these electrode materials. A comparison of the capacitive characteristics of the electrodes using two-electrode scheme was carried out.
\end{abstract}

\section{Introduction}

Supercapacitors are prospective energy storage devices. They are attractive because of high power, long life cycle compared to batteries, and their operation is pollution free [1]. Carbon materials are used as electrode materials for supercapacitors. With the development of the market for nanocarbon materials, researchers are increasingly using these materials with varying degrees of success as electrode materials for supercapacitors.

Most researchers, in order to fully assess the prospects for the use of electrode material in storage devices, carry out tests in two-electrode cell in a series of tests according to a three-electrode scheme. The aim of the work was to study the carbon nanomaterials as electrode materials for supercapacitors using a two-electrode connection scheme.

\section{Experimental}

\subsection{Preparation of electrode material}

In this work, three types of carbon materials (thermally expanded graphite, carbon nanofibers, and activated carbon) were synthesized and investigated.

-Corresponding author: popovmaxvik@gmail.com 


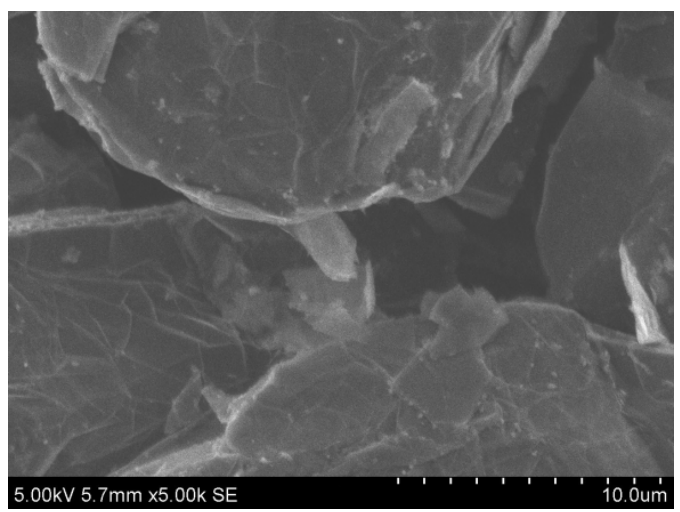

Fig. 1. SEM images of expanded graphite.

Expanded graphite (EG) is a carbon material characterized by low density and the presence of macro- and mesopores in its composition (see Fig. 1). TEM was obtained by heat treatment of intercalated graphite (graphite bisulphate) in the dynamic heating mode. The intercalated graphite was heated in a furnace at a predetermined heating rate $\left(20^{\circ} \mathrm{C} / \mathrm{min}\right)$ to a temperature of $400^{\circ} \mathrm{C}[2]$.

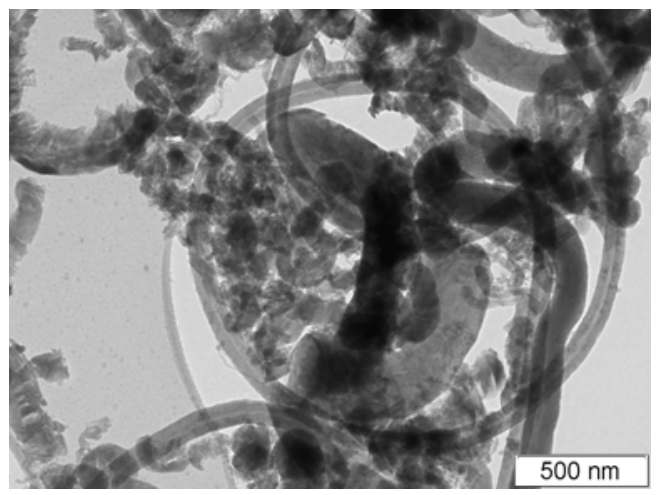

Fig. 2. TEM image of carbon nanofibers.

Carbon nanofibers (CNFs) is a mesoporous material with a nested cone structure [3]. CNFs were synthesized by catalytic decomposition of light $\mathrm{C}_{1}-\mathrm{C}_{4}$ hydrocarbons. Propane was used as the hydrocarbon. The propane decomposition process was carried out on a BTRS Jn flow-through catalytic unit (Autoclave Engineers, USA) at a temperature of $600^{\circ} \mathrm{C}$ on a 50 wt. $\% \mathrm{Ni}-40$ wt. $\% \mathrm{Cu}-10$ wt. $\% \mathrm{SiO}_{2}$ catalyst. Granulated carbon nanofibers material is mainly represented by nanofibers with a diameter of 15-120 nm (Fig. 2). 


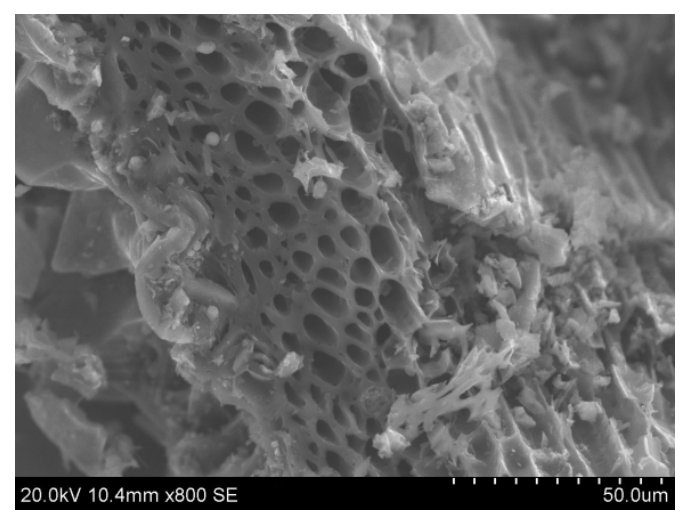

Fig. 3. SEM image of activated carbon.

The third material used in the work was activated carbon material (AC), carbon obtained from rice husks by its controlled combustion [4]. The original rice husk was acid etched, washed with water, dried, and preliminarily burned in a closed reactor with smoke suction and amorphous carbon trapping. The ash was a very soft material and easily crushed to less than $45 \mu \mathrm{m}$ (Fig. 3). The resulting coal was dried and subjected to chemical activation with an aqueous solution of sodium carbonate with a concentration of $13 \mathrm{wt}$. $\%$.

\subsection{Electrochemical testing}

The experiments were carried out on an Elins P-30SM potentiostat. The sample was prepared as follows: a sample of carbon nanomaterial weighing $0.015 \mathrm{~g}$ was mixed with carbon black (approximately $20 \%$ of the sample weight). A 3-mg-sample was taken from the resulting mixture. A weighed portion was formed using vaseline oil and applied to a graphite rod (working electrode). The specific capacity was measured at a sweep rate from 2 to $10 \mathrm{mV} / \mathrm{s}$ in a solution of $3.5 \mathrm{M}$ sulfuric acid at room temperature. During the experiments, cyclic voltammograms $(\mathrm{CV})$ were created.

The experiments were carried out in a two-electrode electrochemical cell consisting of a graphite electrode and a platinum plate with an area of $10 \mathrm{~cm}^{2}$. The electrolyte was a solution of sulfuric acid $\left(3.5 \mathrm{M} \mathrm{H}_{2} \mathrm{SO}_{4}\right)$.

\subsection{Characterization}

Scanning electron microscopy (SEM) was used for investigation of surface of carbon materials using Hitachi SU-8000. Transmission electron microscopy was used to investigate the morphology of carbon nanofibers (JEOL JEM-2200FS).

The texture characteristics of the carbon materials were studied using low-temperature nitrogen adsorption at $77 \mathrm{~K}$ on a Quantachrome NOVA 1000e unit. Specific surface area (A) was calculated using the BET method. The specific surface area of pores remaining after filling the micropores with the adsorbate $\left(\mathrm{A}_{t}\right)$ was calculated by the comparative t-method of de Boor and Lippens, the statistical thickness of the adsorption film for which was calculated using the de Boor equation.

\section{Results and discussion}

Table 1 shows the texture characteristics of the initial carbon materials. 
Table 1. Texture characteristics of initial carbon nanomaterials.

\begin{tabular}{|c|c|c|c|c|}
\hline Sample & $\boldsymbol{A}, \mathbf{~ m}^{\mathbf{2}} / \mathbf{g}$ & $\boldsymbol{A}_{\mathbf{m}}, \mathbf{~ m}^{\mathbf{2}} / \mathbf{g}$ & $\boldsymbol{d}_{\text {pore }}, \mathbf{n m}$ & $\boldsymbol{V}, \mathbf{c m}^{\mathbf{3}} / \mathbf{g}$ \\
\hline CNF & 248 & 116 & 9 & 0.535 \\
\hline EG & 759 & 455 & 4 & 0.817 \\
\hline AC & 145 & 114 & 3 & 0.109 \\
\hline
\end{tabular}

Table 1 shows the values of the specific surface area $\left(A, \mathrm{~m}^{2} / \mathrm{g}\right)$, the specific surface area of micropores $\left(A_{m}, \mathrm{~m}^{2} / g\right)$, the average pore diameter $\left(d_{\text {pore }}, n m\right)$, as well as the total pore volume $\left(\mathrm{V}, \mathrm{cm}_{3} / \mathrm{g}\right)$. EG sample had the largest specific surface area, with the area of micropores $455 \mathrm{~m}^{2} / \mathrm{g}$. AC can be considered as a predominantly microporous material with a specific surface area of micropores $A_{m}=114 \mathrm{~m}^{2} / g$. It was shown that activated carbon has a minimum pore size with a minimum pore volume, but in turn, expanded graphite has a maximum specific surface area. The results of testing the specific capacity depending on the sweep rate in a two-electrode electrochemical cell are presented in Table 2.

Table 2. Specific capacity of carbon materials determined using two-electrode scheme.

\begin{tabular}{|c|c|c|c|c|}
\hline \multirow{2}{*}{ Sample no. } & \multirow{2}{*}{ Carbon material } & \multicolumn{4}{|c|}{ Specific capacity at various sweep rate, $\mathrm{C}_{\mathrm{sp}}, \mathrm{F} / \mathrm{g}$} \\
\cline { 3 - 5 } & & 10 & 5 & 2 \\
\hline 1 & $\mathrm{CNF}$ & 5 & 7 & 14 \\
\hline 2 & $\mathrm{EG}$ & 1 & 1 & 2 \\
\hline 3 & $\mathrm{AC}$ & 8 & 13 & 37 \\
\hline
\end{tabular}

According to the data presented in Table 2, the AC sample is characterized by the highest specific capacity. It is noted that the specific capacity of a carbon material is the greater, the smaller its specific surface area, average pore diameter and total pore volume. The specific capacity values obtained during the tests are consistent with the data on the study of the specific capacity of multi-walled carbon nanotubes and multi-walled carbon nanotubes doped with nitrogen (MWCNTs) $[5,6]$.

\section{Conclusion}

The work shows that carbon materials such as expanded graphite, carbon nanofibers, and activated carbon obtained from rice husks can be used as an electrode material for supercapacitors. It has been shown that activated carbon, having lower texture characteristics, such as specific surface area, total pore volume, possesses specific capacity higher than those of carbon nanofibers and expanded graphite.

This work was financially supported by the State task of Ministry of Higher Education and Science (project code FSUN-2020-0008).

\section{References}

1. D. Chen, K. Jiang, T. Huang, G. Shen, Recent advances in fiber supercapacitors: Materials, device configurations, and applications. Adv. Mater. 32, 1901806 (2020)

2. A.G. Bannov, A.A.Timofeeva, V.V. Shinkarev, K.D. Dyukova, A.V. Ukhina, E.A. Maksimovskii, S.I. Yusin, Prot. Met. Phys. Chem. Surf. 50, 183 (2014)

3. M.V. Popov, A.G. Bannov, Mater. Today-Proc. 31, 489 (2020)

4. P.M. Yeletsky, V.A. Yakovlev, M.S. Mel'gunov, V.N. Parmon, Micropor. Mesopor. Mater. 121, 34 (2009) 
5. P.M. Korusenko, Russ. J. Omskiy Nauchny Vestnik 4, 80 (2020)

6. A.V. Shchegolkov, A.V. Shchegolkov, F.F. Komarov, Vestnik VGUIT [Proceedings of VSUET]. 82, 1 (2020). 